Artigos

Volume 10 - $2020 \mid$ n. 6

\title{
O Impacto da Expansão do Fies entre 2010 e 2017 no Cumprimento Estratégico 12.6 do PNE (2014-2024)
}

\author{
Danubia Fernandes Alves \\ Cristina Helena Almeida de Carvalho \\ Universidade de Brasília (UnB), Brasília/DF - Brasil
}

\section{Resumo}

O artigo tem por objetivo analisar o impacto da expansão de novos contratos de Financiamento Estudantil (Fies) na trajetória da educação superior privada entre 2010 e 2017 e na estratégia 12.6 do Plano Nacional de Educação entre 2014 e 2017, no Brasil. Trata-se de um estudo descritivo/analítico amparado por pesquisa documental. Os dados quantitativos e financeiros foram tratados por meio de estatística descritiva e obtidos nos Censos da Educação Superior do INEP e no Serviço de Informação ao cidadão (SIC) do FNDE. Os dados revelaram que houve priorização do programa como política de expansão da educação superior privada, até 2014, em congruência com a estratégia 12.6 do PNE. Os ajustes promovidos em 2015 refletiram na queda de novos contratos firmados, bem como na redução de ingressantes na educação superior privada, entre 2015 e 2017, fato que poderia ter sido ainda maior na ausência do programa de empréstimo estudantil. Conclui-se que o Fies perdeu o poder indutor como política pública.

Palavras-chave: Plano Nacional de Educação. Fies. Educação Superior Privada. Financiamento.

\section{The Impact of Expansion of the FIES between 2010 and 2017 in Strategic Compliance 12.6 of PNE (2014-2024)}

\begin{abstract}
The purpose of this article is to analyze the impact of the expansion of new Student Funding contracts (Fies) in the trajectory of private higher education between 2010 and 2017 and in the strategy 12.6 of the National Education Plan between 2014 and 2017 in Brazil. This is a descriptive / analytical study supported by documentary research. The quantitative and financial data were treated through descriptive statistics and obtained from the Higher Education Census of INEP and the Citizen Information Service (SIC) of FNDE. The data revealed that until 2014 the program was prioritized as a policy for the expansion of private higher education, in line with PNE strategy 12.6. The adjustments promoted in 2015 reflected in the decrease of new contracts signed, as well as in the reduction of enrollments in private higher education between 2015 and 2017, which could have been even greater in the absence of the student loan program. It is concluded that the Fies lost the inductive power as public policy.
\end{abstract}

Keywords: National Education Plan. Fies. Private Higher Education. Funding. 
O Impacto da Expansão do Fies entre 2010 e 2017 no Cumprimento Estratégico 12.6 do PNE (2014-2024)

\section{Introdução}

O Plano Nacional de Educação (PNE) vigente é uma política de Estado que estabelece um total de 254 estratégias que devem orientar a política educacional brasileira em todos os níveis e modalidades de ensino no período de 2014 a 2024.

A viabilidade do PNE como política de Estado demandou discussões sobre as diretrizes, metas e estratégias em uma disputa política no que diz respeito ao financiamento, pois de sua garantia dependem a execução e o sucesso do plano. No que tange à educação superior, a meta 12 prevê "elevar a taxa bruta de matrícula na educação superior para cinquenta por cento e a taxa líquida para trinta e três por cento da população de dezoito a vinte e quatro anos, assegurada a qualidade da oferta e expansão para, pelo menos, quarenta por cento das novas matrículas, no segmento público".

A meta 12 envolve a consecução de 21 estratégias, que traçam ações para o alcance do percentual indicado sobre as taxas bruta e líquida de matrícula nos cursos de graduação no Brasil entre 2014 e 2024. As ações previstas contam com a atuação preponderante do governo federal, e, ao mesmo tempo, favorece o setor privado para o alcance da meta, através da ampliação da participação de dois programas federais: o Prouni ${ }^{1}$ e o Fies. A análise da expansão do Fies, prevista na estratégia $12.6^{2}$ do PNE vigente, permitirá verificar o seu impacto na meta 12 do PNE (2014-2024). Cabe destacar que, embora as estratégias $12.5^{3} \mathrm{e}$ $12.20^{4}$ também se refiram à expansão do Fies, estas não serão tratadas neste artigo, uma vez que a pesquisa não abrange o estudo a respeito da ampliação das políticas de inclusão e de assistência estudantil aos beneficiários do Fies e dos benefícios concedidos no financiamento estudantil, respectivamente.

Metodologicamente, trata-se de um estudo descritivo/analítico, amparado pela pesquisa bibliográfica e documental. Os dados quantitativos e financeiros serão tratados por meio de estatística descritiva.

1 O Programa Universidade para Todos (Prouni) tem como finalidade a concessão de bolsas de estudo integrais e parciais em cursos de graduação e sequenciais de formação específica, em instituições de ensino superior privadas. Este foi criado pelo Governo Federal em 2004 e institucionalizado pela Lei 11.096, em 13 de janeiro de 2005, e oferece, em contrapartida, isenção de tributos àquelas instituições que aderem ao programa. Ver a este respeito em: <http://www.prouniportal.mec.gov.br/>. Acesso em: 25 jun. 2018.

2 Estratégia 12.6: expandir o financiamento estudantil por meio do Fundo de Financiamento Estudantil - FIES, de que trata a Lei $n^{\circ} 10.260$, de 12 de julho de 2001, com a constituição de fundo garantidor do financiamento, de forma a dispensar progressivamente a exigência de fiador. Disponível em: <http://www.planalto.gov.br/ccivil_03/_ato20112014/2014/lei//13005.htm>. Acesso em: 25 dez. 2017.

3 Estratégia 12.5: ampliar as políticas de inclusão e de assistência estudantil dirigidas aos (às) estudantes de instituições públicas, bolsistas de instituições privadas de educação superior e beneficiários do Fundo de Financiamento Estudantil (FIES), de que trata a Lei $n^{\circ} 10.260$, de 12 de julho de 2001, na educação superior, de modo a reduzir as desigualdades étnico-raciais e ampliar as taxas de acesso e permanência na educação superior de estudantes egressos da escola pública, afrodescendentes e indígenas e de estudantes com deficiência, transtornos globais do desenvolvimento e altas habilidades ou superdotação, de forma a apoiar seu sucesso acadêmico. Disponível em: <http://www.planalto.gov.br/ccivil_03/_ato2011-2014/2014/lei/113005.htm>. Acesso em: 30 out. 2018.

4 Estratégia 12.20: ampliar, no âmbito do Fundo de Financiamento ao Estudante do Ensino Superior (Fies), de que trata a Lei no 10.260, de 12 de julho de 2001, e do Programa Universidade para Todos (Prouni), de que trata a Lei no 11.096 , de 13 de janeiro de 2005, os benefícios destinados à concessão de financiamento a estudantes regularmente matriculados em cursos superiores presenciais ou a distância, com avaliação positiva, de acordo com regulamentação própria, nos processos conduzidos pelo Ministério da Educação (BRASIL, 2014). Disponível em: <http://www.planalto.gov.br/ccivil_03/_ato2011-2014/2014/lei//13005.htm>. Acesso em: 30 out. 2018. 
O Impacto da Expansão do Fies entre 2010 e 2017 no Cumprimento Estratégico 12.6 do PNE (2014-2024)

O presente trabalho pretende verificar em que medida o acréscimo de novos contratos do Fies, no período de $2010^{5}$ a 2017 , contribuiu para a expansão de ingressantes na educação superior privada, verificando o seu efeito como "mecanismo de financiamento do acesso na educação superior privada presencial” (QUEIROZ, 2018, p. 59). Vale salientar que a entrada na educação superior privada não se dá por meio do Fies, no entanto, conforme foi apurado por Queiroz (2018), a grande maioria dos contratos são firmados no ano de ingresso nos cursos de graduação. Com o intuito de analisar o impacto do programa no cumprimento do PNE em vigência, foi feito um recorte entre 2014 e 2017, intervalo que compreende o primeiro ano do PNE até o último ano das informações disponíveis nas fontes de dados utilizadas neste artigo.

Os dados referentes aos novos contratos e o financiamento do Fies foram obtidos por meio do Serviço de Informação ao Cidadão (SIC) do FNDE. Os gastos financeiros do programa foram atualizados pelo IPCA a preços de 2017. Foram utilizados os dados do Censo da Educação Superior produzidos pelo INEP de 2010 a 2017 quanto aos ingressantes na educação superior e na educação superior privada.

O artigo está estruturado em três seções, além da introdução e das considerações finais. Na primeira seção, são descritas as principais mudanças ocorridas nas regras do Fies entre 2010 e 2017. Na segunda seção, apresenta-se a evolução comparativa nos gastos com o Fies empenhados e executados no período em tela ${ }^{6}$. Na terceira seção verifica-se em que medida os novos contratos de empréstimo estudantil impactaram na expansão do número de ingressantes na educação superior e na educação superior privada, além dos efeitos do programa no cumprimento da estratégia 12.6 do PNE para o período de 2014 a 2017. A título de considerações finais, destacam-se o seu papel na expansão da educação superior privada e as principais perspectivas futuras quanto ao desenvolvimento do programa.

\section{As Mudanças no FIES entre 2010 e 2017}

O PNE tem uma posição estratégica nas políticas educacionais, pois é uma lei que determina diretrizes, metas e estratégias das ações públicas na melhoria da educação brasileira. É uma política de Estado e, portanto, está sujeita às influências dos cenários políticos e econômicos. De acordo com Dourado (2016), estes são desafios a serem superados na materialização do PNE, principalmente na regulamentação de algumas metas e estratégias.

A relevância do tema financiamento na educação deve-se ao fato de que a materialização de políticas educacionais depende primeiramente de uma política de financiamento, visto que a existência de recursos financeiros, que subsidiem as políticas públicas educacionais, torna real e materializa as metas e estratégias de um plano de educação.

$\mathrm{Na}$ educação superior, os programas Fies e Prouni compõem políticas públicas que se apresentam como instrumentos que beneficiam a iniciativa privada. No que tange ao Fies, pretende-se verificar como a mudança na sistemática do programa, ocorrida entre 2010 e

\footnotetext{
5 A partir de 2010 , com a Lei $n^{\circ} 12.202 / 2010$, o Fies foi amplamente reformulado, inclusive passando a ser denominado Fundo de Financiamento Estudantil. Além disso, em 2010, o Fundo Nacional de Desenvolvimento da Educação passou a ser o agente operador do programa para novos contratos.

6 Até o momento, há informações disponíveis no Censo da Educação Superior até 2017.
} 
O Impacto da Expansão do Fies entre 2010 e 2017 no Cumprimento Estratégico 12.6 do PNE (2014-2024)

2017, impacta na meta 12 do PNE (2014-2024), uma vez que permite analisar em que medida essa política contribui para a expansão do número de ingressantes na educação superior privada, o que possibilitará dimensionar o seu papel como política pública de crédito educativo por meio do endividamento estudantil.

O Fies foi criado por meio da Medida Provisória $n^{0} 1.827 / 1999$, sendo que esta foi posteriormente reeditada pela Medida Provisória $n^{\circ} 2.094-28 / 2001$, que foi convertida na Lei $n^{\circ} 10.260 / 2001$. É um fundo de natureza contábil e surgiu como forma de financiar, com recursos públicos federais, o pagamento de mensalidades nas instituições de ensino superior privadas. O acesso estudantil a esse programa depende do atendimento de requisitos definidos em regulamentos próprios.

Conforme já abordados por Queiroz e Carvalho (2017; 2018) e Queiroz (2018), é importante salientar que, entre 2000 e 2009, o Fies apresentou um caráter mais restritivo de acesso, tendo em vista as taxas de juros mais elevadas, os prazos de carência e amortização mais reduzidos, além da necessidade de apresentação de idoneidade cadastral por parte do estudante, exigência de fiador, limite de financiamento reduzido, e definição de cursos considerados prioritários para a obtenção do crédito estudantil.

Entre 2010 a 2014, houve flexibilização das regras do Fies, como redução da taxa de juros, aumento do limite a ser financiado, carência e amortização ampliados, avaliação de idoneidade cadastral apenas para fiador e a criação do Fundo Garantidor de Operações de Crédito Educativo (Fgeduc), para alunos carentes (QUEIROZ, 2018). A partir do segundo semestre de 2015, as regras para o Fies voltaram a ser restritivas, com a redução do limite financiável, acréscimo na taxa de juros, redução do prazo de amortização em um ano, redefinição de cursos prioritários e regiões prioritárias e limitação da renda familiar mensal bruta per capita de até 2,5 salários mínimos. Por fim, a exigência de nota mínima no Enem obedeceu ao mesmo critério válido desde 2005 para o acesso ao Prouni (QUEIROZ, 2018).

Quadro 1 - Principais regras do Fies entre 2010 e 2016

\begin{tabular}{|c|c|c|}
\hline & 2010- 2014 (fase expansionista) & 2015-2017 (fase restritiva) \\
\hline Taxa de juros & $3,4 \%$ a.a. & $6,5 \%$ a.a. \\
\hline Carência & $\begin{array}{l}18 \text { meses a partir do mês } \\
\text { subsequente à conclusão do curso }\end{array}$ & $\begin{array}{l}18 \text { meses a partir do mês subsequente à } \\
\text { conclusão do curso }\end{array}$ \\
\hline $\begin{array}{l}\text { Prazo de amortização do } \\
\text { contrato }\end{array}$ & $\begin{array}{l}3 \text { vezes a duração do curso }+12 \\
\text { meses }\end{array}$ & 3 vezes a duração do curso \\
\hline $\begin{array}{l}\text { Pagamento de juros } \\
\text { trimestrais (utilização e } \\
\text { carência) }\end{array}$ & $\mathrm{R} \$ 50$ & Até R\$ 150 \\
\hline Renda familiar & Até 20 salários mínimos & $\begin{array}{l}\text { 2015: } 2,5 \text { salários mínimos per capita } \\
\text { 2016: } 3 \text { salários mínimo per capita }\end{array}$ \\
\hline Nota do Enem & $\begin{array}{l}\text { Ter realizado o Enem no ano } \\
\text { anterior }\end{array}$ & $\begin{array}{l}\text { Nota mínima de } 450 \text { pontos na média do } \\
\text { Enem e nota diferente de zero na redação }\end{array}$ \\
\hline Nota SINAES & Conceitos de qualidade 3 & $\begin{array}{l}\text { Prioritariamente IES com conceitos de } \\
\text { qualidade } 5\end{array}$ \\
\hline
\end{tabular}

Fonte: Resende (2018, p. 42). 
O Impacto da Expansão do Fies entre 2010 e 2017 no Cumprimento Estratégico 12.6 do PNE (2014-2024)

No Quadro 1 é possível perceber que houve mudanças nas condições de pagamento e nos critérios de escolha do Fies comparando as fases expansionista e restritiva. As mudanças ocorridas a partir de 2015 impactaram nos critérios de pagamento e na focalização do programa, e foram necessárias para o aprimoramento do programa. Foram alterações significativas, que ocorreram de forma muito rápida, e "onde o setor privado teve pouco tempo para se adaptar às novas regras" (RESENDE, 2018, p. 68). Essas condições refletiram no número de novos contratos formalizados e no impacto nos ingressantes na educação superior privada.

A seguir, serão analisados os gastos relativos ao programa entre 2010 e 2017, verificando como a política de financiamento evoluiu de acordo com as fases expansionista e restritiva do programa.

\section{Os Gastos com o FIES entre os Anos de 2010 a 2017}

$\mathrm{Na}$ sistemática de financiamento do Fies, ocorrem transferências de títulos da dívida pública federal ${ }^{7}$, por meio dos Certificados Financeiros do Tesouro (CFT-E), e a responsável pela emissão destes títulos é a Secretaria do Tesouro Nacional (STN). Dessa maneira, o Tesouro Nacional arca mensalmente com as despesas educacionais dos alunos perante às IES até o término do curso. "Em contrapartida aos pagamentos, é registrado um crédito a favor do Tesouro Nacional, onde a dívida é acrescida dos juros definidos na assinatura do contrato pelo estudante" (QUEIROZ, 2018, p. 14). "A utilização dos Certificados Financeiros do Tesouro série-E (CFT-E) pelas IES restringe-se ao abatimento de débitos junto ao Tesouro Nacional, sobretudo no pagamento de dívidas previdenciárias" (CARVALHO, 2011, p. 350).

Conforme abordado por Queiroz (2018), a composição de gastos com o programa abrange: o pagamento das mensalidades, o pagamento das taxas de administração, a existência de subsídio implícito ${ }^{8}$ e os custos com a inadimplência. Neste artigo foram investigados os gastos totais com o Fies empenhados e pagos, sendo que, para este último, considerados aqueles pagos em cada exercício financeiro, somados aos restos a pagar. Não foram tratados neste artigo os dados relativos às dotações orçamentárias, porque a pesquisa não abordou estudo sobre as receitas do Fies.

\footnotetext{
A Dívida Pública Federal (DPF) refere-se a todas as dívidas contraídas pelo governo federal para financiamento do seu déficit orçamentário, nele incluído o refinanciamento da própria dívida, e para outras operações com finalidades específicas, definidas em lei. Atualmente, toda a Dívida Pública Federal em circulação no mercado nacional é paga em moeda nacional e captada por meio da emissão de títulos públicos, sendo por essa razão definida como Dívida Pública Mobiliária Federal interna (DPMFi). Ver a este respeito: <http://www.tesouro.fazenda.gov.br/>. Acesso em: 04 jun 2018.

8 "No caso do Fies, os subsídios implícitos são o diferencial entre os juros contratualmente aplicados às dívidas dos estudantes, 3,4\% a.a. até 2015 e 6,5\% a.a. e o custo de captação dos recursos pelo Tesouro Nacional (taxa Selic). Em outras palavras, é a diferença entre a quantia que o governo deverá receber do beneficiário do Fies no futuro e o valor que desembolsará para honrar os títulos públicos emitidos como forma de pagamento pelo curso" (RESENDE, 2018, p. 62).
} 
O Impacto da Expansão do Fies entre 2010 e 2017 no Cumprimento Estratégico 12.6 do PNE (2014-2024)

Gráfico 1 - Valores empenhados x Valores pagos

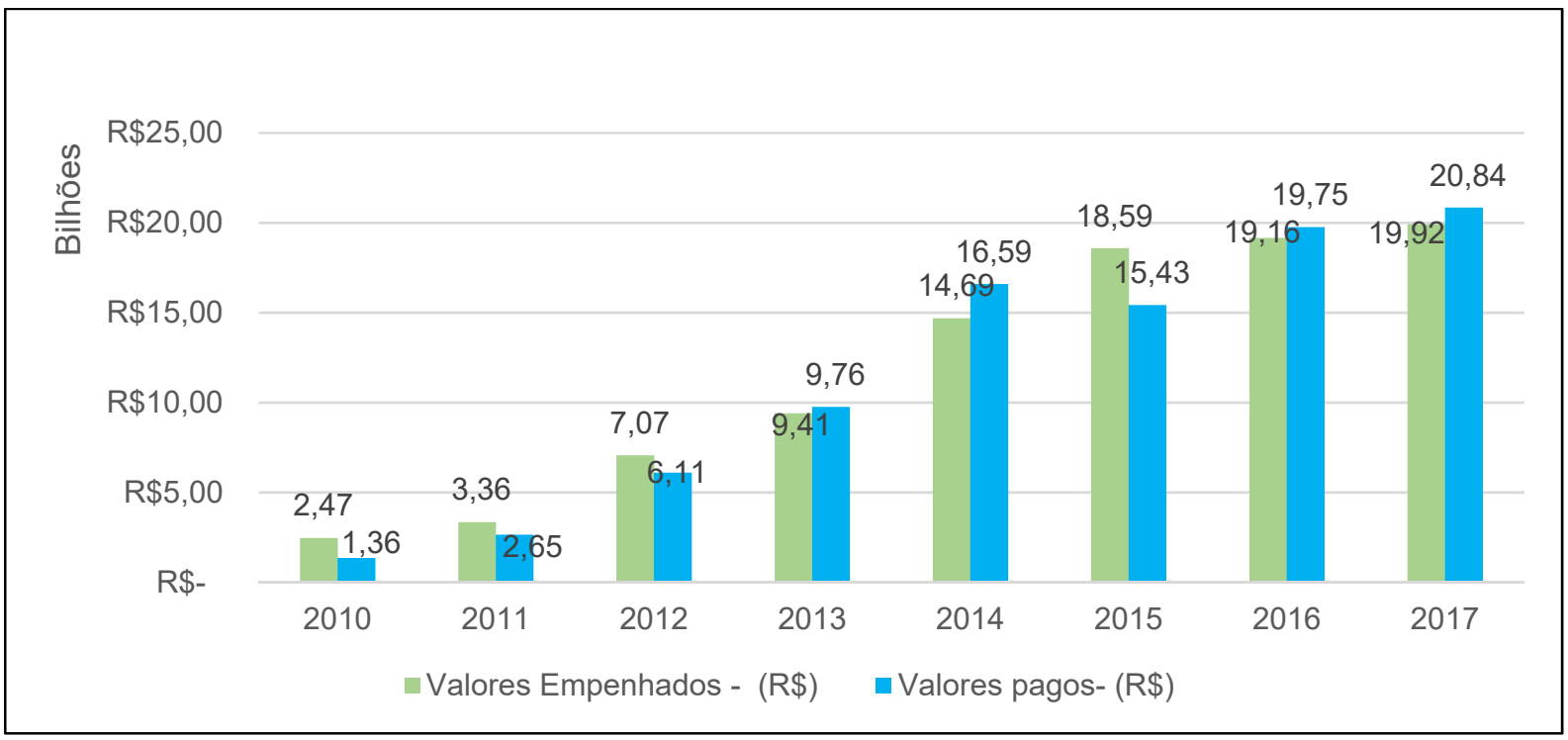

Fonte: Elaboração das autoras com base em SIC-FNDE (2018). Dados atualizados pelo IPCA a preços de 2017.

Como é possível observar no Gráfico 1, entre 2010 e 2017 houve em aumento de $705 \%$ nos valores empenhados com o programa. Em relação aos valores pagos, verifica-se acréscimo de $1430 \%$. De forma diferente do que acontece com o financiamento das políticas sociais em geral e da educação superior federal em particular, submetidos a cortes sucessivos, é possível perceber que, a partir de 2013, com exceção do ano de 2015, os valores pagos superaram os valores empenhados, demonstrando a priorização da política pública destinada à iniciativa privada.

O Gráfico 1 ainda demonstra que, nos quatro anos característicos da fase expansionista do Fies, houve um aumento expressivo no financiamento dos contratos em vigência. Além de regras mais flexíveis, neste período o subsídio implícito era de $47 \%$, e, portanto, os estudantes deveriam arcar com o reembolso de $53 \%$ do valor do financiamento (NASCIMENTO; LONGO, 2016 , p. 17). A partir do $2^{\circ}$ semestre de 2015, houve aumento da coparticipação dos estudantes, devendo estes arcar com $73 \%$ do valor financiado, diante de um subsídio implícito de $27 \%$. Ainda de acordo com Nascimento e Longo (2016), o principal parâmetro a afetar a taxa de reembolso do financiamento nesses dois cenários, ou seja, a taxa de juros anual do Fies, quase dobrou: passou de $3,4 \%$ a.a. para $6,5 \%$ a.a. Como reflexo dessa mudança na política de financiamento, houve ampliação do retorno aos cofres públicos dos gastos com o financiamento estudantil.

A partir do $2^{\circ}$ semestre de 2015 , houve restrições nas regras do programa no sentido de dar sustentabilidade fiscal e reduzir os custos relativos ao subsídio implícito e à inadimplência. Além disso, a alteração das regras do Fies foi necessária para aperfeiçoar o programa, com o objetivo de focalizar o atendimento em grupos mais necessitados.

Na seção seguinte será tratado o impacto do Fies na estratégia 12.6 da meta 12 do PNE (2014-2024), mediante a análise da relação entre novos contratos e ingressantes na educação superior privada de 2010 a 2017. 
O Impacto da Expansão do Fies entre 2010 e 2017 no Cumprimento Estratégico 12.6 do PNE (2014-2024)

\section{O Impacto da Expansão do FIES na Estratégia 12.6 do PNE (2014- 2024)}

O PNE (2014-2024) prevê na meta 12 “[...] elevar a taxa bruta de matrícula na educação superior para cinquenta por cento e a taxa líquida para trinta e três por cento da população de dezoito a vinte e quatro anos, assegurada a qualidade da oferta e expansão para, pelo menos, quarenta por cento das novas matrículas, no segmento público". Dentre as 21 estratégias, este artigo focaliza a análise na expansão do Fies que está prevista na estratégia 12.6, "[...] expandir o financiamento estudantil por meio do Fundo de Financiamento Estudantil (Fies), de que trata a Lei $n^{\circ} 10.260$, de 12 de julho de 2001, com a constituição de fundo garantidor do financiamento (FGEDUC), de forma a dispensar progressivamente a exigência de fiador". Em outras palavras, pretende-se verificar em que medida a expansão dos novos contratos do Fies impactou no número de ingressantes da educação superior privada presencial ${ }^{9}$ e na educação superior presencial de 2010 a 2017. A escolha desse recorte temporal deve-se à necessidade de verificar como o programa foi tratado no período anterior e posterior ao PNE (2014-2024).

As informações sobre os novos contratos foram obtidas mediante o SIC-FNDE. Cabe destacar que os novos contratos são aqueles firmados pela primeira vez, dando início ao contrato de empréstimo estudantil. Por sua vez, "a fase de utilização é o período, em média de quatro anos, em que o aluno está estudando e utilizando o financiamento de forma regular" (QUEIROZ, 2018, p. 27). Os contratos em fase de utilização do Fies não foram tratados neste artigo, devido à ausência de informações disponíveis para o ano de 2016 e $2017^{10}$.

Os dados dos Censos da Educação Superior de 2010 a 2014 demonstram que os ingressantes na educação superior privada presencial aumentaram nesse período cerca de $37 \%$, passando de 1.366 .191 para 1.878 .483 de ingressantes. De acordo com o SIC-FNDE, o crescimento de novos contratos do Fies foi muito superior entre 2010 e 2014, em 863\%, passando de 76.035 para 732.676 de novos contratos firmados. O extraordinário acréscimo ocorreu no período em que o Fies apresentava critérios mais flexíveis em sua política de financiamento, dentre os quais, pode-se destacar, o acréscimo no prazo de amortização, a ampliação do público alvo do programa, limite de prazo de financiamento estendido e a taxa de juros anual reduzida.

A fase restritiva do Fies, quando houve a mudança dos critérios de financiamento, ocorreu a partir de 2015 e isso refletiu na diminuição do número de novos contratos formalizados. Dentre os critérios exigidos, cabe destacar a exigência de nota mínima no Exame Nacional do Ensino Médio (ENEM) (450 pontos) e nota maior que zero na redação, redução do limite da renda familiar e aumento da taxa de juros anual do financiamento. A

9 Até 31/12/2017, o Fies oferecia financiamento estudantil apenas para cursos presenciais.

10 A informação sobre os contratos em fase de utilização de estudantes entre 18 e 24 anos de idade, permitiria verificar o impacto do Fies na meta 12 do PNE (2014-2024), através do cálculo das taxas bruta e líquida de matrículas, relacionando os dados sobre o número de contratos nessa situação e o quantitativo de matrículas na educação superior e educação superior privada presenciais, estes dados, extraídos do Censo da Educação Superior. Tal comparação restou prejudicada tendo em vista a ausência de informações disponíveis sobre esses contratos por parte do FNDE e a insuficiência de dados no Relatório de Auditoria do Fies (2016), elaborado pelo TCU, que contém o quantitativo de contratos em utilização do Fies até 2015, mas sem discriminação por faixa etária. 
redução dos novos contratos do Fies na educação superior privada foi expressiva, apresentando uma queda de 76\% nos novos contratos entre 2014 e 2017.

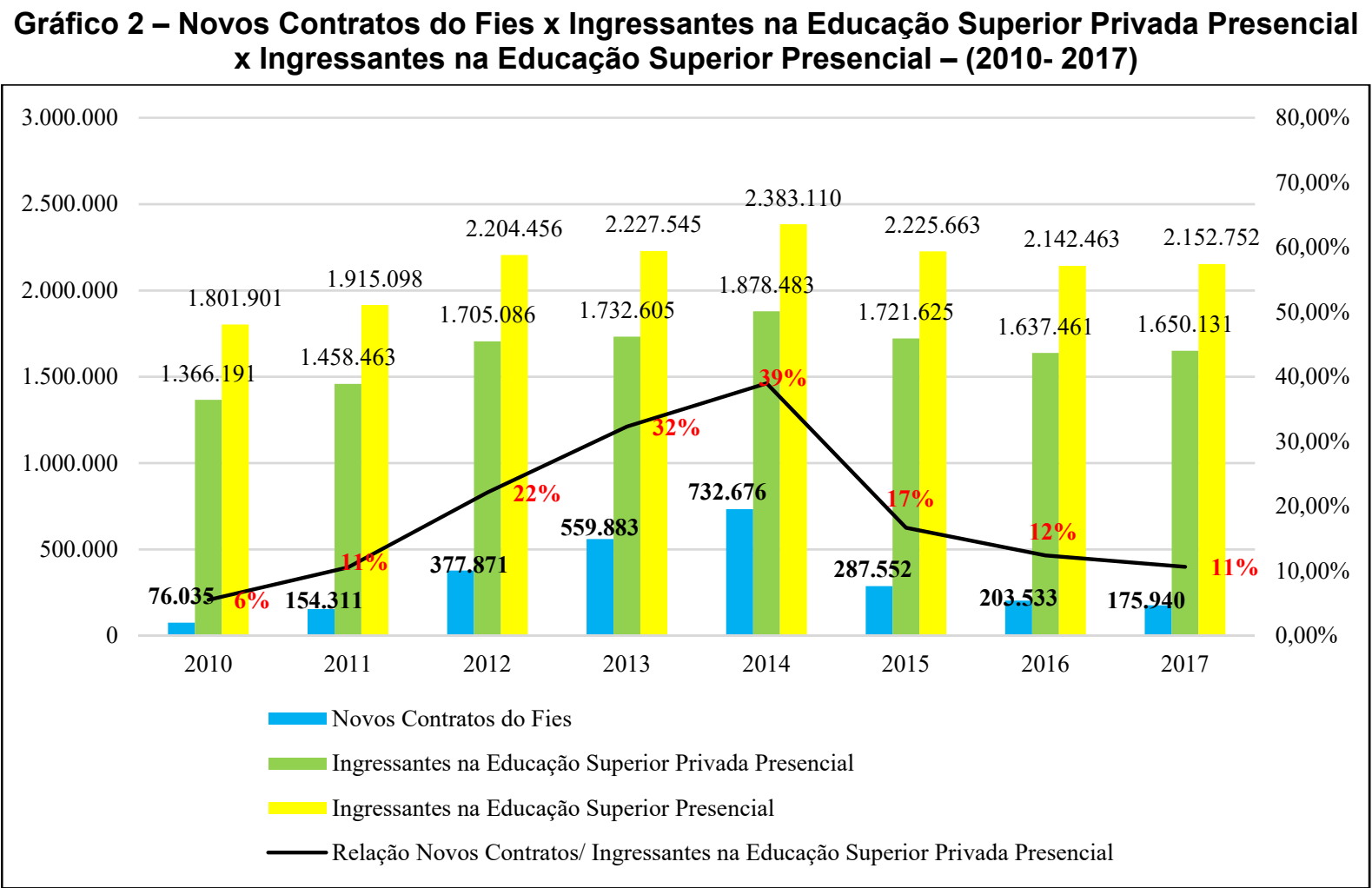

Fontes: SIC/FNDE (2018) - Novos contratos (2010-2017) e Sinopses estatísticas da educação superior - ingressantes (quadro 4.1) - Inep (2010-2017).

Pode-se visualizar o impacto dos novos contratos do Fies no número de ingressantes na educação superior privada presencial, sendo que estes correspondiam a $6 \%$ em 2010, e passaram para $39 \%$ em 2014, corroborando com o período de flexibilização das regras do Fies, cuja prioridade do governo federal foi a implementação de políticas anticíclicas ${ }^{11}$. Em 2015 , os novos contratos representavam $17 \%$ de ingressantes na educação superior privada e, em 2016 , apenas $12 \%$, chegando a $11 \%$ em 2017 . As quedas sucessivas na proporção de novos contratos vis a vis aos pleiteantes ocorreram em consequência da reformulação do programa, que levaram à queda na demanda por novos contratos do Fies, associada às condições econômicas desfavoráveis das famílias em período de crise.

No que tange à evolução dos ingressantes na educação superior presencial, houve um aumento de $32 \%$ entre 2010 e 2014 , passando de 1.801 .901 para 2.383 .110 novos alunos. Quando se compara com o número de ingressantes na educação superior privada presencial, cujo aumento, nesse período, foi de $37 \%$, houve semelhança quanto ao crescimento. Porém, ao comparar esses dois dados com o crescimento do número de novos contratos, cujo crescimento expressivo foi de $863 \%$, conclui-se que houve priorização do Fies como política

11 Uma política econômica anticíclica consiste na intervenção Estatal mediante aumento dos gastos públicos nos períodos de depressão, incorrendo assim o Estado para gerar demanda agregada que estimularia o investimento e reduziria o desemprego. Além disso, esta política pode amenizar ou até eliminar os efeitos negativos dos desequilíbrios dos ciclos econômicos. Esses desequilíbrios são ciclos que envolvem uma alternância de períodos com crescimento relativamente acelerado com períodos de relativa estagnação ou declínio. Para mais detalhes, acessar: <http://economia.estadao.com.br/noticias/geral,politicas-anticiclicasimp-,1153971>; <http://peritiaeconomica.com.br/keynes-teoria-anticiclica>. 
O Impacto da Expansão do Fies entre 2010 e 2017 no Cumprimento Estratégico 12.6 do PNE (2014-2024)

de expansão da educação superior pela via privada. As alterações ocorridas nas regras do Fies, a partir de 2015, impactaram negativamente no número de novos contratos formalizados em relação ao número de ingressantes na educação superior privada presencial, apresentando uma queda de $6 \%$ entre 2015 e 2017 , passando de $17 \%$ para $11 \%$. Já o número de novos contratos em relação ao total de ingressos na educação superior presencial, apresentou queda de $5 \%$ entre 2015 e 2017 , passando de $13 \%$ para $8 \%$.

É importante salientar que, nos anos de 2015 e 2016, houve queda nos ingressantes na educação superior presencial e na educação superior privada presencial, que poderia ter sido maior na ausência do Fies. Em 2017, esses dois dados obtiveram discreto crescimento: de $0,77 \%$ na educação superior presencial, passando de 2.142.463 ingressantes, em 2016, para 2.152.752, em 2017, e de $0,50 \%$ na educação superior privada presencial, passando de 1.637.461 ingressantes, em 2016, para 1.650.131, em 2017.

Por fim, quanto ao impacto na estratégia 12.6 do PNE, percebe-se que, no primeiro ano do Plano, em 2014, o programa tinha grande importância na educação superior privada presencial, representando quase $40 \%$ dos ingressos pela iniciativa privada, e cerca de $30 \%$ das admissões na educação superior presencial. Vale salientar que a queda de ingressantes na educação superior presencial, ocorrida a partir de 2014, provavelmente está associada ao arrefecimento do programa de crédito educativo, que perdeu fôlego como fator indutor da expansão da educação superior.

\section{Considerações Finais}

O Plano Nacional de Educação, uma política de Estado, demanda discussões sobre formas para a sua materialização, tendo em vista que apresenta metas e estratégias para as políticas educacionais no decênio 2014-2024. Sobre o Fies, a estratégia 12.6 prevê a sua ampliação como instrumento da política de expansão e permanência na educação superior. Porém, mudanças nos cenários político e econômico brasileiros provocaram modificações na forma de operacionalização do programa, com o objetivo de mantê-lo sustentável do ponto de vista financeiro e buscando uma focalização da política para atender ao público mais carente.

Sobre o financiamento do Fies, verificou-se que os gastos se mostraram crescentes durante a série histórica de 2010 a 2017, mesmo após a redução dos novos contratos a partir de 2015. Os gastos totais - mensalidades, taxas de administração, subsídio implícito e inadimplência - cresceram de forma expressiva, exigindo que o governo federal arcasse com os dispêndios de contratos já formalizados diante de uma redução de receitas próprias do Fies, conforme analisado por Queiroz (2018). Percebe-se que, diante dos gastos apresentados nos anos de 2013, 2014, 2016 e 2017, os valores pagos superaram os valores empenhados, demonstrando a priorização da política pública destinada à iniciativa privada.

Por fim, quanto ao impacto na estratégia 12.6 do PNE, os dados demonstram que os critérios adotados na fase expansionista do Fies propiciaram aumento excepcional no número de novos contratos entre 2010 e 2014, provocando um efeito crescente na expansão da educação superior privada presencial no primeiro ano do PNE atual. Entretanto, as regras mais flexíveis tornaram o programa pouco sustentável financeiramente e, por isso, mudanças nos critérios de aquisição do financiamento foram adotadas, a partir de 2015 , reduzindo a proporção de novos contratos em relação aos ingressantes na educação superior privada 
O Impacto da Expansão do Fies entre 2010 e 2017 no Cumprimento Estratégico 12.6 do PNE (2014-2024)

presencial, na educação superior como um todo e, consequentemente, na estratégia 12.6 do PNE.

É importante reafirmar que informações como número de contratos em fase de utilização de estudantes entre 18 e 24 anos, e número de matrículas na educação superior privada de estudantes nessa faixa etária, permitiriam verificar o impacto do Fies nas taxas de matrículas bruta e líquida discriminadas na meta 12. Embora os microdados do Censo da Educação Superior contenham dados sobre o quantitativo de matrículas discriminadas por faixa etária, até o presente momento as informações sobre contratos em fase de utilização por faixa etária não foram disponibilizadas pelo FNDE. No Relatório de Auditoria do TCU (2016), há informações sobre quantitativo dos empréstimos estudantis em fase de utilização até o ano de 2015, mas os dados não estão discriminados por faixa etária, inviabilizando a comparação entre contratos do Fies em utilização e matrículas na educação superior privada presencial.

Por fim, as perspectivas futuras do Fies mostram que o programa perdeu o poder indutor, que havia sido assumido como estratégia para atingir a meta 12 do PNE. Em 2017, foram 175.940 novos contratos, ou seja, houve uma queda de $76 \%$ em relação à 2014 , primeiro ano do PNE. No entanto, os custos do programa não foram reduzidos em virtude do amplo passivo de contratos que ainda não estão em fase de amortização, chegando aos percentuais de aumento de $35 \%$ nos valores empenhados e de $25 \%$ nos valores pagos com o programa entre 2014 e 2017. Isso acontece uma vez que o Fies foi excluído da lei do teto dos gastos federais ${ }^{12}$, que limita o crescimento das despesas primárias à variação da inflação, por se tratar de despesas financeiras que não se submetem à regra fiscal. Em outras palavras, o Fies não está sujeito a qualquer forma de constrangimento de natureza fiscal proveniente dessa Emenda Constitucional. No entanto, a partir de 2018, uma nova reconfiguração do programa está em andamento, cujo impacto tem sido de ínfima adesão.

\section{Referências}

BRASIL. Medida provisória no 1.827-1, de 24 de junho de 1999. Dispõe sobre o Fundo de Financiamento ao Estudante do Ensino Superior e dá outras providências. Diário Oficial da União, Brasília, 1999. Disponível em: <http://www.planalto.gov.br/ccivil_03/mpv/ antigas/1827-1.htm>. Acesso em: 25 dez. 2017.

BRASIL. Medida provisória no 2.094-28, de 13 de junho de 2001. Dispõe sobre o Fundo de Financiamento ao Estudante do Ensino Superior e dá outras providências. Diário Oficial da União, Brasília, 2001a. Disponível em: <http://www.planalto.gov.br/ccivil_03/mpv/Antigas_ 2001/2094-28.htm>. Acesso em: 25 dez. 2017.

BRASIL. Lei no 10.260, de 12 de julho de 2001. Dispõe sobre o Fundo de Financiamento ao estudante do Ensino Superior e dá outras providências. Diário Oficial da União, Brasília, 2001b. Disponível em: <http://www.planalto.gov.br/ccivil_03/leis/leis_2001/l10260.htm>. Acesso em: 25 dez. 2017.

BRASIL. Lei no 12.202, de 14 de janeiro de 2010. Altera a Lei no 10.260, de 12 de julho de 2001, que dispõe sobre o Fundo de Financiamento ao Estudante do Ensino Superior - FIES

12 Emenda Constitucional No 95, de 2016. Altera o Ato das Disposições Constitucionais Transitórias, para instituir o Novo Regime Fiscal, e dá outras providências. Disponível em: <http://www.planalto.gov.br/ccivil_03/Constituicao/Emendas/Emc/emc95.htm> Acesso em: 21 set. 2018. 
O Impacto da Expansão do Fies entre 2010 e 2017 no Cumprimento Estratégico 12.6 do PNE (2014-2024)

(permite abatimento de saldo devedor do FIES aos profissionais do magistério público e médicos dos programas de saúde da família; utilização de débitos com o INSS como crédito do FIES pelas instituições de ensino; e dá outras providências). Diário Oficial da União, Brasília, 2010. Disponível em: <http://www.planalto.gov.br/ccivil_03/_ato20072010/2010/Lei/L12202.htm>. Acesso em: 14 set. 2018.

BRASIL. Lei 13.005, de 25 de junho de 2014. Aprova o Plano Nacional de Educação e dá outras providências. Diário Oficial da União, Brasília, 2014. Disponível em: <http://www.planalto.gov.br/ccivil_03/_ato2011-2014/2014/lei//13005.htm>. Acesso em: 25 dez. 2017.

BRASIL. Emenda Constitucional $\mathrm{N}^{\circ}$ 95, de 15 de dezembro de 2016. Altera a Ato de Disposições Constitucionais Transitórias, para instituir o novo Regime Fiscal, e dá outras providências. Diário Oficial da União, Brasília, 2016a. Disponível em: <http://www.planalto. gov.br/ccivil_03/Constituicao/Emendas/Emc/emc95.htm>. Acesso em: 21 set. 2018.

BRASIL. Tribunal de Contas da União. Relatório de Auditoria do Tribunal de Contas da União. Brasília, 2016b. Disponível em: <http://portal.tcu.gov.br/data/files/08/43/F7/B1/51B985 10784389852A2818A8/011.884- 2016-9_FIES_.pdf> Acesso em: 07 set. 2018.

BRASIL. Ministério da Fazenda. Emissões direta de títulos da Dívida Pública Mobiliária Federal interna - DPMFi. Brasília, 2017a. Disponível em: <http://www.t esourotransparente.gov.br/>. Acesso em: 11 nov. 2017.

BRASIL. Ministério da Fazenda. Relatório sobre o aprimoramento metodológico do impacto primário do Fies - 2017. Brasília, 2017b. Disponível em: <http://www.tesouro.fazenda.gov.br/>. Acesso em: 11 nov. 2017.

BRASIL. Fundo Nacional de Desenvolvimento da Educação. Dados sobre número de novos contratos e gastos com o Fies. Serviço de Informação ao Cidadão. Brasília, 2018a.

BRASIL. Ministério da Educação. Prouni - Programa Universidade para Todos. Brasília, 2018b. Disponível em: <http://www.prouniportal.mec.gov.br/o-programa>. Acesso em: 8 jan. 2018.

BRASIL. Instituto Nacional de Estudos e Pesquisas Educacionais Anísio Teixeira. Sinopse Estatística da Educação Superior - 2010-2017. Brasília: Inep, 2018c. Disponível em: <http://portal.inep.gov.br/basica-censo-escolar-sinopse-sinopse>. Acesso em: 06 maio 2018.

CARVALHO, Cristina Helena Almeida de. A Política Pública para a Educação Superior no Brasil (1995-2008): ruptura e/ou continuidade? 2011. 465 f. Tese (Doutorado em Economia) - Instituto de Economia, Universidade Estadual de Campinas, Campinas, 2011.

DOURADO, Luiz Fernandes. Plano Nacional de Educação: política de Estado para a Educação brasileira. Brasília: Inep, 2016.

NASCIMENTO, Paulo A. Meyer M.; LONGO, Gustavo Frederico. Qual o custo implícito do Fies para o contribuinte brasileiro?. Radar: tecnologia, produção e comércio exterior, Brasília, Instituto de Pesquisa Aplicada Econômica - Ipea, v. 46, p. 13-21, ago. 2016. Disponível em: <http://ipea.gov.br/portal/index.php?option=com_content\&view=article\&id= 28508\&ltemid =8>. Acesso em: 07 set. 2018. 
O Impacto da Expansão do Fies entre 2010 e 2017 no Cumprimento Estratégico 12.6 do PNE (2014-2024)

QUEIROZ, Jacqueline Clara. Fundo de financiamento estudantil (Fies) - 2010 a 2015 : mecanismo de financiamento da democratização e permanência na educação superior privada. 2018. 114 f. Dissertação (Mestrado em Educação) - Universidade de Brasília, Brasília, 2018.

QUEIROZ, Jacqueline Clara; CARVALHO, Cristina Helena Almeida de. Fundo de Financiamento Estudantil (FIES) - A composição e a evolução dos recursos e dos gastos financeiros do Fies no período de 2000 a 2015. In: ENCONTRO ANUAL FINEDUCA, 5., 2017, Natal. Anais... Natal: Universidade Federal do Rio Grande do Norte, 2017. Disponível em: <http://www.fineduca.org.br/anais-fineduca/edicao-atual/eixo-politicas> Acesso em: 17 set. 2018.

QUEIROZ, Jacqueline Clara; CARVALHO, Cristina Helena Almeida de. O financiamento do Fundo de Financiamento Estudantil (FIES) - 2000 a 2015: a evolução e composição das receitas e dos custos financeiros do programa. In: UNIVERSITAS, 26., 2018, Belo Horizonte. Anais... Belo Horizonte: Universidade Federal de Minas Gerais, 2018. Disponível em: <http://www.redeuniversitas.com.br/2018/09/sairam-os-anais-do-xxvi-seminario-da.html>. Acesso em: 14 set. 2018.

RESENDE, Manoela Vilela Araújo. Crédito educativo: uma análise comparada sobre focalização e sustentabilidade financeira em programas de financiamento estudantil no Brasil, Estados Unidos e Austrália. 2018. 152 f. Dissertação (Mestrado em Políticas Públicas e Desenvolvimento) - Instituto de Pesquisa Econômica Aplicada (IPEA), Brasília, 2018.

Danubia Fernandes Alves possui graduação em Química pela Universidade de Brasília (2008) e pós-graduação em Educação Ambiental e sustentabilidade (2012) pela Faculdade da Grande Fortaleza. Mestranda em Educação pela Universidade de Brasília. Membro da Rede Universitas/BR. Atualmente é servidora federal da Universidade de Brasília (UnB) no cargo de Técnica em Assuntos Educacionais.

ORCID: http://orcid.org/0000-0003-0371-2778

E-mail: danubia2019@gmail.com

Cristina Helena Almeida de Carvalho possui graduação em Ciências Econômicas pela Universidade Católica de Santos (1991), mestrado em Ciências Econômicas pela Universidade Estadual de Campinas (2002) e doutorado em Ciências Econômicas pela Universidade Estadual de Campinas (2011), na área de Política Social. Tem experiência em docência e pesquisa em Política Educacional, sobretudo em expansão e financiamento da educação superior. Atualmente, é Professora Adjunta IV do Departamento de Planejamento e Administração da Educação (PAD) da Faculdade de Educação da Universidade de Brasília (UNB).

ORCID: http://orcid.org/0000-0003-3667-3904

E-mail: cristinahelena@unb.br

Recebido em 22 de fevereiro de 2019 Aprovado em 14 de abril de 2019 


\section{Editores do volume 10}

Márcia Aparecida Jacomini - Universidade Federal de São Paulo, Brasil

José Marcelino de Rezende Pinto - Universidade de São Paulo, Brasil

\section{Comitê Editorial}

Nalú Farenzena - Universidade Federal do Rio Grande do Sul, Brasil

Juca Gil - Universidade Federal do Rio Grande do Sul, Brasil

Theresa Adrião - Universidade Estadual de Campinas, Brasil

Ângelo Ricardo de Souza - Universidade Federal do Paraná, Brasil

\section{Conselho Editorial}

\section{Alejandro Morduchowicz}

Universidad Pedagógica, Provincia de Buenos Aires, Argentina

Andréa Barbosa Gouveia

Universidade Federal do Paraná, Brasil

Fernanda Saforcada

Universidade de Buenos Aires, Argentina

Jacques Velloso

Universidade de Brasília, Brasil

João Monlevade

Senado Federal, Brasil

Jorge Abrahão de Castro

Instituto de Pesquisa Econômica Aplicada / IPEA, Brasil

Lisete Regina Gomes Arelaro

Universidade de São Paulo, Brasil

Luis Carlos Sales

Universidade Federal do Piauí, Brasil

Luiz de Sousa Junior

Universidade Federal da Paraíba, Brasil

Luiz Fernandes Dourado

Universidade Federal de Goiás, Brasil

Magna França

Universidade Federal do Rio Grande do Norte, Brasil

Marcos Edgar Bassi

Universidade Federal de Santa Catarina, Brasil

Maria Angélica Pedra Minhoto

Universidade Federal de São Paulo, Brasil

Maria Beatriz Luce

Universidade Federal do Rio Grande do Sul, Brasil

Maria Dilnéia Espíndola Fernandes

Universidade Federal de Mato Grosso do Sul, Brasil

Nelson Cardoso do Amaral

Universidade Federal de Goiás, Brasil

Nicholas Davies

Universidade Federal Fluminense, Brasil

Robert E. Verhine

Universidade Federal da Bahia, Brasil

Romualdo Portela de Oliveira Universidade de São Paulo, Brasil

Rosana Gemaque Rolim

Universidade Federal do Pará, Brasil

Rubens Barbosa de Camargo

Universidade de São Paulo, Brasil

Theresa Adrião

Universidade Estadual de Campinas, Brasil

Tristan McCowan

University of London, Reino Unido

Vera Jacob

Universidade Federal do Pará, Brasil

Vera Peroni

Universidade Federal do Rio Grande do Sul, Brasil

Vitor Henrique Paro

Universidade de São Paulo, Brasil

\section{Equipe editorial}

Apoio ao Comitê Editorial: Caio Cabral da Silva

Diagramação, Revisão de português e normalização: Edson Leonel de Oliveira

Revisão de inglês: Ananyr Porto Fajardo

Fineduca - Revista de Financiamento da Educação

Associação Nacional de Pesquisa em

Financiamento da Educação

e-mail: revista.fineduca@gmail.com | site: http://seer.ufrgs.br/fineduca 